Ich muss es mir für einen andern Ort vorbehalten, von diesem Gesichtspunkte aus die von mir anfgestellte Theorie zu discutiren, und bemerke nur hier, dass sie sich sehr wohl mit der Annahme einer solchen Electrolyse in Uebereinstimmung bringen liesse.

\title{
Ueber Milchsäurebildung und Glycogenschwund bei der Todtenstarre.
}

Von

R. Boehm in Leiprig.

In einer aus dem physiologischen Institute zu Breslau hervorgegangenen Abhandlung über die Milchsäurebildung und den Glycogenverbrauch im quergestreiften Muskel bei der Thätigkeit und bei der Todtenstarre (dieses Archiv Bd. 46, pag. 63) hat M. Werther Ergebnisse mitgetheilt, welche mit den Befunden nicht übereinstimmen, welche ich im Jahre 1880 (dieses Archiv Bd. 23) beziiglich des Einflusses der Todtenstarre auf den Glycogengehalt des Muskelfleisches erhalten hatte. Werther hat eine bedeutende Abnahme des Glyeogens gefunden, während ich bei Einhaltung bestimmter Cantelen keine Verminderung des Glycogengehaltes des Muskels bei der Starre nachweisen konnte.

Es wird mir in nächster Zeit nicht möglich sein, auf diesem Gebiete weiter experimentell zu arbeiten. Da indessen der Leser der Werther'schen Abhandlung leicht den Eindruck gewinnen kann, als wären die von mir gefundenen Thatsachen durch die gegentheiligen Beobachtungen Werther's einfach wieder aus der Welt geschafft und die Frage wieder auf dem Standpunkte angelangt, auf welchem sie sich vor meiner Arbeit befand, so sehe ich mich genöthigt, Folgendes in aller Kürze hervorzuheben.

Meine Versuche beweisen, dass bei der Entwickelung der Todtenstarre eine Abnahme des Glycogengehaltes des Muskels der Katze nicht stattzufinden braucht. Die Belege hierfür finden sich in meiner oben citirten Abhandlung. 
Ich wüsste nicht, wodurch immer ihre Beweiskraft in Frage gestellt werden könnte. Der Glycogenschwund im Muskel nach dem Tode, wie er unter verschiedenen Bedingungen, namentlich bei höheren Temperaturen unzweifelhaft stattfindet und wie ich ihn selbst oft genug beobachtet habe, muss also eine andere Ursache baben als die Todtenstarre. Es mag sein, dass Fänlnissprocesse im engeren Sinne dabei nicht allein die Rolle spielen, die ich ihnen zuschreiben zu können glaubte.

Vorläufig läuft alles auf die Frage hinaus, ob es zulässig ist, anzunehmen, dass die bei der Starre gebildete Milchsäure aus dem Muskelglycogen entsteht. Dagegen spricht aber nach wie vor,

1) dass sich die Starre voll entwickeln kann, ohne dass der Glycogengehalt sich verändert, und

2) ganz besonders der Umstand, dass die bei der Starre entstehende Milchsäuremenge in gar keinem Verhältnisse steht zu der vorhandenen Glycogenmenge, wie das ein Blick auf Tabelle V, pag. 59 meiner Abhandlung lehrt. Das Fleisch einer Hungerkatze, welches im frischen Zustande nur $0,036 \%$ Glycogen aufwies, enthielt im starren Zustande $0,56 \%$ Milchsäure, genan so viel wie das einer anderen gut gefütterten Katze, in welchem zwanzig mal so viel $(0,71 \%)$ Glycogen enthalten war.

Diese Thatsachen können durch die Angaben Werther's nicht mehr in Frage gestellt werden. Es wird sich lediglich darum handeln, den Ursachen weiter nachzuforschen, welche unter bestimmten Verhältnissen den Glycogenschwund herbeifibren. 